\title{
Persistent Alterations in Biological Profiles in Women With Abuse Histories: Influence of Premenstrual Dysphoric Disorder
}

\author{
Susan S. Girdler, \\ Department of Psychiatry, University of North Carolina at Chapel Hill \\ Jane Leserman, \\ Department of Psychiatry, University of North Carolina at Chapel Hill \\ Robertas Bunevicius, \\ Department of Psychiatry, University of North Carolina at Chapel Hill \\ Rebecca Klatzkin, \\ Department of Psychology, University of North Carolina at Chapel Hill \\ Cort A. Pedersen, and \\ Department of Psychiatry, University of North Carolina at Chapel Hill \\ Kathleen C. Light \\ Department of Psychiatry, University of North Carolina at Chapel Hill
}

\section{Abstract}

Objective-To examine dysregulation in biological measures associated with histories of abuse in women and whether women with premenstrual dysphoric disorder (PMDD) differ in their dysregulation.

\begin{abstract}
Design-Twenty-five women meeting prospective criteria for PMDD and 42 non-PMDD controls underwent structured interview to determine abuse histories and lifetime Axis I diagnoses, excluding those with current Axis I disorders or using medications.
\end{abstract}

Major Outcome Measures-Plasma cortisol and norepinephrine (NE), heart rate (HR), blood pressure (BP), and vascular resistance index (VRI) were assessed at rest and in response to mental stress.

\begin{abstract}
Results-A greater proportion of PMDD women had prior abuse compared with non-PMDD women. Regardless of PMDD status, all abused women had lower plasma NE and higher HRs and tended to have lower plasma cortisol at rest and during stress. Abused women also reported more severe daily emotional and physical symptoms. Greater VRI and BP at rest and during stress were seen only in PMDD women with abuse.
\end{abstract}

Conclusion-There is persistent dysregulation in stress-responsive systems in all abused women that cannot be accounted for by current psychiatric illness or medications, and PMDD women may be differentially more vulnerable to the impact of abuse on measures reflecting $\alpha$-adrenergic receptor function.

\footnotetext{
Copyright 2007 by the American Psychological Association

Correspondence concerning this article should be addressed to Susan S. Girdler, CB \#7175, Medical Research Building A, University of North Carolina, Chapel Hill, NC 27599-7175. E-mail: susan_girdler@med.unc.edu.
} 


\title{
Keywords
}

premenstrual dysphoric disorder; abuse; stress; norepinephrine; cortisol

\begin{abstract}
Abuse rates for women in the United States are sobering. Population-based national surveys have indicated that $13 \%-27 \%$ of women were sexually abused as children (Badgley et al., 1984; Finkelhor, Hotaling, Lewis, \& Smith, 1990; MacMillan et al., 1997). When adult sexual abuse, battering, and other forms of physical abuse are included, more than one third of women from the general population have had these experiences (Resnick, Kilpatric, Dansky, Saunders, $\&$ Best, 1993). The public health significance of abuse in women is underscored by the wellestablished links between histories of abuse and psychiatric (Kendler et al., 2000) as well as medical illness (Felitti et al., 1998; Leserman et al., 1996; McCauley et al., 1997). Animal models provide ample evidence that severe or repeated stress exposure early in life leads to long-term changes in neurobiology, as reflected in alterations in stress response systems that persist throughout life (Bremner \& Vermetten, 2001). On the basis of preclinical as well as clinical evidence, it has been hypothesized that such persistent alterations in neurobiological systems known to be stress responsive may contribute to the development of psychiatric illness in women with abuse histories (Bremner \& Vermetten, 2001; Heim, Newport, Bonsall, Miller, $\&$ Nemeroff, 2001).
\end{abstract}

The stress response system that has been most studied to date in relation to traumatic or abuse histories in humans is the hypothalamic-pituitary-adrenal (HPA) axis. The results of these studies have been mixed with most (Heim et al., 2001; Newport, Heim, Bonsall, Miller, \& Nemeroff, 2004; Resnick, Yehuda, Pitman, \& Foy, 1995; Stein, Yehuda, Koverola, \& Hanna, 1997; Yehuda, Giller, Levengood, Southwick, \& Siever, 1995), although not all (Heim et al., 2000b; Young, Tolman, Witkowski, \& Kaplan, 2004) finding evidence for lower cortisol concentrations or blunted cortisol reactivity to challenge in individuals with trauma or abuse histories. Fewer studies have examined noradrenergic function related to trauma or abuse in humans. However, taken together, the results of those studies have suggested increased noradrenergic activity in adults with prior traumatic stress (for a review, see Bremner \& Vermetten, 2001).

It is important to note that many of the studies investigating HPA or noradrenergic function in women with prior abuse histories have been met with interpretive issues in examining the impact of prior abuse on persistent neuroendocrine dysregulation, as the majority of these studies included women with current psychiatric illness or who were taking psychotropic agents (Heim et al., 2000b; Lemieux \& Coe, 1995; Metzger et al., 1999; Orr et al., 1998; Stein et al., 1997). Indeed, the important interactive effects of current depression and histories of abuse on HPA axis function have been documented (Heim et al., 2000b; Kaufman et al., 1997). However, a report by Heim et al. (2001) provided the strongest evidence to date that histories of abuse have persistent effects on HPA axis function in women in the absence of current depression or medication use. In that study, adult women with a history of childhood sexual or physical abuse and no current major depression or medication use displayed greater adrenocorticotropic hormone (ACTH) concentrations following corticotrophin-releasing hormone stimulation and blunted plasma cortisol concentrations following ACTH stimulation relative to women with childhood abuse plus current depression, women with current depression but no abuse, and healthy controls. These results suggested that there may be sensitization of the anterior pituitary and counterregulatory adaptation of the adrenal cortex in abused women even in the absence of current depression (Heim et al., 2001).

Research from our laboratory has also obtained evidence for persistent dysregulation in stress response systems associated with prior sexual or physical abuse in the absence of current Axis 
I disorders or medication use in women with premenstrual dysphoric disorder (PMDD). Relative to the general population, PMDD women have significantly greater rates of lifetime sexual and physical abuse (rates > 60\%; Girdler et al., 2003; Golding \& Taylor, 1996; Golding, Taylor, Menard, \& King, 2000; Paddison et al., 1990). Results from our prior studies have suggested that these women may be more vulnerable to the effects of prior abuse in measures reflecting noradrenergic function as only PMDD women with abuse histories displayed greater resting and stress-induced heart rates (HRs) and systolic blood pressure (SBP; Bunevicius, Hinderliter, Leserman, Pedersen, \& Girdler, 2005), as well as increased $\beta$-adrenergic receptor responsivity coupled with lower circulating plasma norepinephrine (NE; Girdler et al., 2003) relative to PMDD women with no abuse history-effects not seen in nonabused, non-PMDD women. In contrast, non-PMDD women with abuse histories had lower plasma cortisol concentrations at rest and in response to stress relative to nonabused, non-PMDD women (Girdler et al., 2003).

Although these earlier studies provided initial evidence that the biological correlates of abuse persist even in the absence of current psychiatric illness and that they may differ for PMDD women, they were limited by our failure to control for differences in histories of psychiatric illness between abused PMDD and abused non-PMDD women, particularly histories of depression. It is well established that histories of depression are more common in abused women (Kendler et al., 2000) and may be more common in those with PMDD (Pearlstein et al., 1990). Our own work (Klatzkin, Morrow, Light, Pedersen, \& Girdler, 2005; Pedersen et al., 1993) and that of Young, Aggen, Prescott, and Kendler (2000) have demonstrated that dysregulation in stress-responsive systems persists even in euthymic women who have a history of depression. For example, Young et al. found persistent elevation in salivary cortisol in women with a history of but no current major depressive disorder relative to never-depressed women. Similarly, a study on thyroid and adrenal measures during pregnancy and the puerperium found significantly elevated plasma cortisol in women during the puerperium who had prior depression relative to women with negative psychiatric histories (Pedersen et al., 1993). Most recently, we documented that women with no current depression but with prior major depressive disorder, minor depression, or adjustment disorder with depressed mood show blunted allopregnanolone responses to mental stress relative to never-depressed women (Klatzkin et al., 2005). Thus, it is possible that the results of Heim et al. (2001) and our own prior studies (Bunevicius et al., 2005; Girdler et al., 2003) documenting persistent alterations in stress-responsive measures in PMDD women with histories of abuse but no current psychopathology reflect the influence of their greater rates of prior depressive episodes and not differential effects of abuse per se.

Consequently, the purpose of this study was twofold. First, it was designed to replicate our earlier work showing a differential impact of abuse on noradrenergic function in PMDD women, as this would implicate noradrenergic mechanisms in the pathophysiology of PMDD. Thus, we recruited an entirely new sample of PMDD and non-PMDD controls for the present study, used structured interview to assess abuse histories, and used psychophysiological techniques to measure indices of noradrenergic and HPA axis function. Second, we sought to extend prior work suggesting persistence of dysregulation in both HPA axis and noradrenergic systems in women with abuse histories by carefully assessing and matching groups for histories of depressive episodes. A tertiary goal was to examine the association of abuse histories with daily symptom ratings in both the follicular and luteal phases of the menstrual cycle.

\section{Method} Subjects

Twenty-five women prospectively diagnosed with PMDD and 42 non-PMDD controls responded to newspaper, radio, or posted advertisements and met all inclusionary-exclusionary 
criteria (see below). To ensure relatively equal proportions of prior depression in PMDD and non-PMDD groups, advertisements targeting women with histories of depression were also used. All subjects were in good health, and none were taking any prescription medication, including oral contraceptives or psychotropic agents. The protocol was approved by the University of North Carolina at Chapel Hill Committee on Protection of the Rights of Human Subjects. Subjects provided written informed consent prior to participation, and each received $\$ 250$ compensation.

\section{Procedures}

Assessment of PMDD—The Prospective Record of the Impact and Severity of Menstrual Symptoms calendar (Reid, 1985) was used to classify both PMDD women and non-PMDD controls. In addition to symptom severity ratings, the Prospective Record of the Impact and Severity of Menstrual Symptoms calendar also incorporates measures of life style impact, life events, and the use of medications. Calendars were completed daily for 2-3 menstrual cycles.

Criteria for PMDD were based on those of the Diagnostic and Statistical Manual of Mental Disorders (4th ed., or DSM-IV; American Psychiatric Association, 1994), which include (a) rating of symptoms as moderate or severe (as opposed to mild) premenstrually, (b) moderate to severe symptoms on at least 3 of the 6 premenstrual days, (c) a total of five or more symptoms premenstrually, (d) at least one moderate to severe emotional symptom, (e) evidence that symptoms affected function, (f) a symptom-free period in the follicular phase, and (g) Criteria 1-6 met on two consecutive menstrual cycles. Non-PMDD control women met the following criteria: (a) not completely asymptomatic during the premenstrual week (i.e., to exclude women biased to nonreporting), (b) having only mild emotional symptoms premenstrually, (c) moderate physical symptoms on fewer than 3 days premenstrually, and (d) no evidence that symptoms affected normal functioning.

\section{Structured Clinical Interviews}

Psychiatric histories: Structured clinical interviews (Structured Clinical Interview for DSMIII-R; Spitzer, Williams, Gibbon, \& First, 1992) based on DSM-IV criteria for Axis I disorders were conducted. All diagnoses were based on a consensus diagnostic session with a psychiatrist (Cort A. Pedersen). For present purposes, women classified with lifetime depression met criteria for either lifetime major depressive disorder (11 non-PMDD, 13 PMDD), minor depressive disorder (4 non-PMDD, 1 PMDD), or adjustment disorder with depressed mood (2 non-PMDD, 1 PMDD). Because lifetime histories of depressive episodes are prevalent in women (Weissman \& Olfson, 1995), 7 months in full remission was required for lifetime depression. For other Axis I disorders, 3 years in full remission was required.

Sexual and physical abuse histories: After administration of the Structured Clinical Interview for $D S M-I I I-R$, subjects were asked about sexual and physical abuse histories using a modified version of a validated interview (Leserman et al., 1996). This interview correlates highly with many indicators of poor health (Leserman, $\mathrm{Li}$, Drossman, \& Hu, 1998), indicating its predictive validity, and the reliability of this interview compared with questionnaire measures of abuse is established (Leserman, Drossman, \& Li, 1995). Sexual abuse included the following experiences in which force or threat of harm was used: (a) sexual touching with hands, mouth, or objects; (b) making the subject touch the perpetrator with hands, mouth, or objects; and (c) making the subject have vaginal or anal intercourse. To meet criteria for sexual abuse incidents as an adult or adolescent, there had to be clear threat of harm or force (pressure for sexual activity was not sufficient). To meet criteria as a child (younger than 14 years of age), the threat of force did not have to be as clearly established if it was implied by the age differential between perpetrator and victim. Physical abuse was defined as incidents separate from sexual abuse that included (a) life threat (being physically attacked with or without a weapon, with the intent 
to kill or seriously injure) and (b) other physical abuse (beat, hit or kicked, bit or burned) by another person-incidents outside the range of normal spanking or kids fighting.

For analytic purposes, we combined sexual and physical abuse experiences in the present study as previous research has shown that both types of abuse are related to numerous indicators of poor health status (Felitti et al., 1998; Leserman et al., 1996). Women were included with childhood (younger than 14 years of age), adolescent (14-19 years of age), or adult (older than 20 years of age) abuse experiences. PMDD and non-PMDD women did not differ in number with first abuse experience in childhood (9 vs. 6 , respectively), in adolescence (1 vs. 3 ), or in adulthood (2 vs. 3). Ten women with abuse histories had experienced both sexual and physical abuse (7 PMDD and 3 non-PMDD), 4 had prior sexual abuse only (1 PMDD and 3 non-PMDD), and 10 had prior physical abuse only (4 PMDD and 6 non-PMDD).

Physiological Recording Procedures-Blood pressure (BP) was recorded noninvasively using the auscultatory technique. An automated blood pressure monitor (Suntech, 4240 Blood Pressure Monitor) was used to measure blood pressure. SBP corresponded to the onset of K-sounds, and diastolic blood pressure (DBP) corresponded to the disappearance of K-sounds. Manual stethoscopic readings were taken initially using a sphygmomanometer to ensure correct placement of the microphone.

Impedance cardiography was used to permit noninvasive monitoring of cardiac performance (Sherwood et al., 1990), including stroke volume, HR, and preejection period. A customdesigned impedance cardiograph (HIC-100, Bioimpedance Technology, Inc., Model 100, Chapel Hill, North Carolina) was used in conjunction with a tetrapolar band electrode configuration to record impedance $\mathrm{dZ} / \mathrm{dt}$ and Zo signals. Impedance and electrocardiogram signals were processed online by specialized computer software (BIT, Chapel Hill, North Carolina) with subsequent manual editing to improve accuracy. For each minute of interest, a 30-s continuous sample of waveforms (obtained concurrently with BP) was processed to generate an ensemble-averaged cardiac cycle, from which stroke volume was determined by means of the Kubicek, Krnegis, Patterson, Witsoe, and Mattson (1966) equation and HR was determined by the mean interbeat interval. Cardiac output and total peripheral resistance for these same minutes were then calculated using standard formulas (Sherwood et al., 1990). To control for group differences in body mass index (see the Results section), stroke volume, cardiac output, and total peripheral resistance were adjusted for individual differences in body size by using body surface area to derive stroke volume index, cardiac index (CI) and vascular resistance index (VRI).

Experimental Procedures-Each subject was tested twice, once during her early follicular phase (Days 2-6) and once 8-12 days after home urine testing (Clearplan Easy®) revealed the luteinizing hormone surge. All cycles were later confirmed to be ovulatory using serum progesterone. Cycle phase at first testing was counterbalanced within groups. Before testing, subjects were instructed to refrain from all over-the-counter medications for $24 \mathrm{hr}$, caffeine for $8 \mathrm{hr}$, and nicotine for $1 \mathrm{hr}$. All laboratory test sessions began between 0730 and 0900 .

Immediately on arriving at the laboratory, subjects were instrumented for cardiovascular monitoring. Next, an IV line was established in an arm vein, and once in place, a curtain was drawn that prevented the subject from viewing the IV. A minimum of 15 min elapsed between establishing the IV and beginning baseline rest. Subjects were then exposed to the following conditions.

Baseline rest: Subjects rested alone and quietly for $10 \mathrm{~min}$. Blood pressure and impedancederived measures were taken at Minutes 1, 3, 5, 7, and 10 and averaged. Blood was sampled 
at Minute 10 for baseline NE and cortisol and for estradiol and progesterone concentrations to verify cycle phase.

Trier Social Stress Test (TSST; Kirschbaum, Pirke, \& Hellhammer, 1993): We used a modified version of the TSST (modified to include serial addition as opposed to serial subtraction). The TSST is a stress test that reliably induces large and consistent HPA and cardiovascular responses (Kirschbaum, Klauer, Filip, \& Hellhammer, 1995; Kirschbaum et al., 1993; Kirschbaum, Prussner, et al., 1995). The TSST involves four components:

1. Pretask instructions: During pretask instructions, subjects were introduced to the "selection committee" who would later listen to their job talk. Subjects were also given the instructions for the mental arithmetic task. The duration of the instruction period averaged $5 \mathrm{~min}$.

2. Speech preparation period: During this period, subjects were left alone for $5 \mathrm{~min}$ to prepare their talk.

3. Job speech: Immediately following the preparation period, the selection committee returned to the testing room and asked the subject to deliver his or her talk describing to the committee why he or she would be the perfect applicant for the position. If the subject finished before $5 \mathrm{~min}$, the committee responded in a standardized way with prepared questions to ensure that the subject spoke for the entire period. Talks were tape recorded, and subjects had the opportunity to earn up to $\$ 10$, based on the committee's ratings of their speech performance. Cardiovascular measures were taken at Minutes 1, 3, and 5 and averaged. Blood was sampled for plasma NE at the end of Minute 2.

4. Paced Auditory Serial Addition Test (PASAT; Gronwall, 1977): The PASAT involves the tape-recorded presentation of numbers from 1 to 9 and lasted $8.5 \mathrm{~min}$. Subjects added each number presented on the tape to the immediately preceding number and stated the answer aloud. There were four series of numbers, with progressively shorter interdigit intervals. The experimenter remained in the room to monitor performance. Subjects had the opportunity to earn up to $\$ 10$, based on the total number of correct additions. Cardiovascular measures were taken once each of the four series and averaged. Blood was sampled for plasma NE at the end of minute 2.

Stress recovery: Subjects rested quietly alone for $10 \mathrm{~min}$. Blood was sampled at the end of this recovery period to capture the delayed plasma cortisol response to the TSST (Kirschbaum, Klauer, et al., 1995; Kirschbaum, Prussner, et al., 1995).

Hormone and Neuroendocrine Assays-Blood for cortisol was collected into ethylenediamine tetraacetic acid-treated tubes, and blood for NE was collected into heparintreated tubes. Tubes were placed immediately on ice and cold centrifuged to separate plasma within a few minutes after collection. Plasma was pipetted into aliquot tubes, rapidly frozen, and maintained at $-80^{\circ} \mathrm{C}$ until assayed. Plasma levels of cortisol were determined by radioimmunoassay using commercial kits from ICN Pharmaceuticals (Hampshire, United Kingdom). The sensitivity of the assay is excellent at $0.07 \mu \mathrm{g} / \mathrm{dL}$. The specificity of the radioimmunoassay for cortisol is high, showing only $0.05 \%-2.2 \%$ cross-reactivity with most similarly structured compounds. Plasma levels of NE were determined using the high performance liquid chromatography technique. The lower limit of quantification with this system is $25 \mathrm{pg} / \mathrm{ml}$, and the intra- and interday coefficients of variation are less than $10 \%$. Serum levels of progesterone were determined with radioimmunoassay kits from ICN Pharmaceuticals, Inc. The specificity of the antiserum for progesterone is very high, showing 
only $0.01 \%-2.5 \%$ cross-reactivity with other steroid compounds. Progesterone levels less than $3 \mathrm{ng} / \mathrm{ml}$ in the luteal phase of the cycle were considered reflective of an anovulatory cycle.

Data Reduction and Analyses-Differences in age and body mass index were analyzed using a 2 (group: PMDD vs. non-PMDD) $\times 2$ (abuse: yes vs. no) analysis of variance (ANOVA), and abuse-related differences in the proportion of women meeting criteria for lifetime Axis I disorders was analyzed using chi-square analyses.

We examined the influence of histories of abuse and the menstrual cycle on cardiovascular and neuroendocrine measures, using 2 (group) $\times 2$ (abuse) $\times 2$ (phase) $\times 3$ (condition: baseline, speech, math) repeated measures ANOVAs with phase and condition as the repeated factors. Where significant interactions emerged, subsequent simple effects analyses were conducted to examine the source of the effect. Finally, the influence of prior abuse on mean daily symptom ratings was examined. To reduce Type I error rates, only five symptoms were examined, representing common and distressing premenstrual symptoms: irritability, anger, depression, headache, and fatigue. Mean follicular and luteal phase symptom scores were based on the average, across two menstrual cycles, of the severity ratings during days 4-9 of the follicular phase and the severity ratings during the 6 days preceding menses (luteal phase). A 2 (group) $\times 2$ (abuse) $\times 5$ (symptom) $\times 2$ (phase) repeated measures ANOVA was used, with symptom and phase as the repeated factors.

\section{Results}

\section{Abuse Histories}

A greater proportion of PMDD women relative to non-PMDD women had histories of both physical abuse ( 11 of 25 vs. 9 of 42 ), $\chi^{2}(1)=3.8, p=.05$, and sexual abuse ( 8 of 25 vs. 6 of $42), \chi^{2}(1)=3.0, p=.08$. Thus, there was a tendency for a greater proportion of PMDD women to be classified with prior abuse (either sexual or physical) relative to non-PMDD women (12 of 25 vs. 12 of 42$), \chi^{2}(1)=2.6, p=.10$.

\section{Demographic Factors and Psychiatric Histories}

Table 1 summarizes selected demographic and psychiatric history variables. Although groups did not differ in age, PMDD women with abuse histories had greater body mass index than did nonabused PMDD women, Group $\times$ Abuse $F(3,66)=3.0, p<.05$. Thus, stroke volume, cardiac output, and total peripheral resistance were adjusted for differences in body size to yield stroke volume index, CI, and VRI.

As expected, all women with histories of abuse $(n=24)$ were more likely to meet criteria for histories of depression than were nonabused women (17 of 24 vs. 16 of 43 ), $\chi^{2}(1)=7.0, p<$. 01. However, the abused PMDD and abused non-PMDD groups did not differ in the proportion with prior depression (67\% and 75\%, respectively), nor did the nonabused groups (46\% and $33 \%$ ). In the PMDD sample only, 33\% of the PMDD women with abuse histories also had histories of posttraumatic stress disorder (PTSD) compared with $0 \%$ of the nonabused PMDD women, $\chi^{2}(1)=5.2, p<.05$, whereas abuse was not associated with different rates of prior PTSD in non-PMDD women.

\section{Cardiovascular and Neuroendocrine Levels at Rest and During Stress}

Effects of Abuse Histories-All women with histories of abuse, regardless of PMDD diagnosis or menstrual cycle phase, exhibited significantly lower plasma NE concentrations at rest and during mental stressors relative to nonabused women, main effect of abuse $F(1,63)$ $=5.3, p<.05$ (see Figure 1). All women with histories of abuse also had significantly greater HR levels at rest and during stressors in both cycle phases, main effect of abuse $F(1,63)=4.0$, 
$p<.05$ (see Figure 2). For cortisol, an Abuse $\times$ Phase trend was obtained, $F(1,63)=3.1, p<$. 10 (see Table 2). Subsequent simple effects analyses conducted separately in the two cycle phases revealed that only in the follicular phase did abused women tend to have lower plasma cortisol at rest and poststress relative to nonabused women, $F(1,63)=2.8, p<.10$, whereas no abuse-related differences existed in the luteal phase.

In addition to the effects of abuse history on HR, plasma NE, and cortisol that were present in all women, we also obtained evidence for a differential effect of abuse in PMDD women for measures of blood pressure and vascular resistance. As illustrated in Figure 3, only for the PMDD women was prior abuse associated with elevated VRI measures at rest and during stress in both cycle phases, Group $\times$ Abuse $F(1,63)=3.9, p=.05$. Similarly, for blood pressure only for PMDD women was prior abuse associated with significantly elevated SBP, Group $\times$ Abuse $F(1,63)=6.7, p<.05$ (see Table 2) and DBP, Group $\times$ Abuse $F(1,63)=5.7, p \times .05$, in both cycle phases (see Figure 4).

There were no group or abuse-related effects for stroke volume index or CI (Table 2). With the exception of cortisol, for each dependent measure significant main effects of condition were obtained, $F \mathrm{~s}(3,61)=3.1-136.7, p \mathrm{~s}<.05$, reflecting the significant change from baseline to stressors. There were no significant Abuse $\times$ Condition interactions, indicating that all group differences summarized above were evident under both baseline and stressor conditions. Failure to observe a significant condition effect for cortisol (i.e., stress effect) was likely due to the fact that we tested all subjects in the morning, when diurnal effects on cortisol are greatest (Kudielka \& Kirschbaum, 2005).

Effects of the Menstrual Cycle-Although, with the exception of cortisol, the overall abuse-related effects described above were evident in both menstrual cycle phases, this is not to say that the menstrual cycle did not influence cardiovascular and neuroendocrine measures. For all women, regardless of abuse or PMDD status, the luteal phase of the menstrual cycle was associated with significantly greater plasma NE concentrations, $F(1,60)=13.2, p<.001$ (see Figure 1); greater HR and CI levels, $F \mathrm{~s}(1,60)=6.4$ and $6.1, p \mathrm{~s}<.05$, respectively (see Table 2 and Figure 2); and lower VRI levels, $F(1,60)=6.1, p<.05$ (see Figure 3), than the follicular phase. There were no cycle-related effects for SBP, DBP, or stroke volume index.

Influence of Abuse on Daily Symptom Ratings-Mean daily severity ratings as a function of PMDD and abuse status are presented in Table 3. As expected, all PMDD women, regardless of abuse history, had greater symptom severity ratings, especially in the luteal phase, Group $\times$ Phase $F(1,62)=39.3, p<.0001$. An overall effect of abuse was also obtained, reflecting the generally greater symptom levels in abused versus nonabused women, $F(1,62)$ $=5.4, p<.05$, collapsed across cycle phase. This was qualified, however, by a Phase $\times$ Symptom $\times$ Abuse $\times$ Group interaction, $F(4,59)=3.5, p<.05$, which was explored by examination of all least-squares means comparisons. These comparisons indicated that in the follicular phase, PMDD women with abuse had greater symptom severity for anger, irritability, depression, and headache than did nonabused PMDD women (all $p$ s <.05), whereas abused, non-PMDD women had greater depression and fatigue ratings than did nonabused, non-PMDD women $(p s<.05)$. In the luteal phase, the only significant effects to emerge regarding abuse histories were for the non-PMDD women, as abused, non-PMDD women had greater irritability $(p<$. 05) than did nonabused, non-PMDD women.

\section{Discussion}

The results of our study add to a divergent yet growing body of knowledge indicating that early life exposure to abuse leads to persistent and long-term dysregulation in stress-responsive systems. Moreover, our study is among the first to demonstrate persistent cardiovascular and 
neuroendocrine dysregulation in women with histories of abuse who are not currently suffering from psychiatric illness or using psychotropic medications. Our study is also among the first to examine noradrenergic mechanisms in adult survivors of abuse. We found that irrespective of PMDD diagnosis or menstrual cycle phase, women with histories of abuse had lower circulating plasma NE concentrations at rest and during stress. Although most clinical studies have reported increased noradrenergic activity in adults with prior traumatic stress, as reflected in circulating NE concentrations or increased responsiveness of the sympathadrenal system (see Bremner, Krystal, Southwick, and Charney, 1996, and Bremner \& Vermetten, 2001, for reviews), this finding may likely reflect the impact of current comorbid PTSD that was present in many of these studies. Indeed, Lemieux and Coe (1995) found that only women with both abuse histories and current PTSD had greater urinary NE concentrations relative to nonabused controls, similar to the finding of Young and Breslau (2004) that individuals with lifetime PTSD had higher urinary catecholamine concentrations than trauma-exposed/never-PTSD and nonexposed groups. Even more relevant to our results is the evidence documented by these same investigators (Young \& Breslau, 2004) indicating an impact of trauma exposure, per se, on urinary catecholamines, as the trauma-exposed/never-PTSD group had significantly lower concentrations than the nonexposed group — a pattern remarkably similar to our finding for reduced plasma NE in abused women free of current PTSD and depression. Young and Breslau suggested that reduced catecholamine concentrations in individuals with histories of traumatic stress may reflect a long-term adaptation to trauma exposure.

It should be noted that our findings of reduced plasma NE coupled with greater HR at rest and during stressors in abused women may at first seem paradoxical, as catecholamines, including $\mathrm{NE}$, act to stimulate HR increases via stimulation of $\beta$-adrenergic receptors. However, this finding is, in fact, consistent both with pharmacological theory and with the findings from our earlier study showing lower circulating plasma NE coupled with increased $\beta$-adrenergic receptor responsivity in PMDD women with histories of abuse (Girdler et al., 2003). Increased $\beta$-adrenoceptor responsivity would be consistent with pharmacological up-regulation of the receptors in response to diminished agonist (i.e., diminished NE) and would mediate, at least in part, the increased HRs that we documented in all abused women in the present study. This hypothesis is speculative, however, as no assessment of $\beta$-adrenoceptor responsivity was made in this study. Nevertheless, we did document alterations in peripheral $\beta$-adrenoceptor function associated with abuse in our prior study (Girdler et al., 2003), and such alterations may have pathophysiological relevance with respect to the mood disturbance seen in abuse. Increased $\beta$-adrenoceptor density has been documented in clinical depression (Leonard, 1997) and is associated with premenstrual symptom severity in PMDD women (Gurguis et al., 1998). Additional studies assessing $\beta$-adrenergic receptor function and relationship to symptoms and mood in abused women are needed to address the pathophysiological role of $\beta$-adrenergic receptors in the psychiatric comorbidity associated with abuse.

Our study also investigated HPA axis function, as reflected in plasma cortisol concentrations. Although only a trend, our finding of lower cortisol in abused women, at least in the follicular phase, is consistent with many studies on HPA axis function in abused women, reporting lower cortisol concentrations or blunted response to challenge (Heim et al., 2001; Newport et al., 2004; Resnick et al., 1995; Stein et al., 1997). However, our results suggest that the hypocortisolemia noted in so many studies of traumatized individuals may represent a persistent effect of the exposure to traumatic stress and is not necessarily a result of current comorbid clinical depression or PTSD or the use of psychotropic medications. Indeed, our findings are consistent with the study by Heim et al. showing blunted plasma cortisol to ACTH challenge in adult women with childhood abuse who were free of current depression and medication use and consistent with the study of Resnick et al. showing that women with a previous history of rape had lower cortisol responses to a subsequent rape than women who were raped but had no previous rape history. These findings, taken together, are in keeping 
with the emerging evidence that chronic or severe stress exposure can result in persistent alterations in neurobiological systems that are stress responsive (Heim et al., 2001) and that this can be manifest in hyporesponsiveness of the system to subsequent stressors, as has been documented in animal models of early life stress and HPA axis function (Coplan et al., 1996; Ladd, Owens, \& Nemeroff, 1996). Hypocortisolemia may have special clinical relevance as recent evidence has indicated that blunted HPA axis function is associated with a number of stress-related bodily disorders (Heim, Ehlert, \& Hellhammer, 2000).

It has been suggested that a genetic vulnerability coupled with early stress in a critical and plastic period of development may result in persistent alterations in neurobiological systems that are known to be stress responsive, resulting in dysregulation in stress responsiveness to even mild stressors in adulthood and forming the basis for the development of mood disorders (Heim et al., 2001). Despite the fact that none of the women in the present study met diagnostic criteria for a current mood disorder, our finding that all women with histories of abuse, who displayed persistent dysregulation in measures reflecting both the HPA axis as well as the sympathetic nervous system, had more severe daily emotional and physical symptom ratings than did nonabused women suggests a persistence of mood disturbance associated with abuse history even in the absence of meeting current clinical criteria. It is interesting to note, however, that greater symptom levels in abused versus nonabused PMDD women were evident only in their follicular phase. Although the reason for this remains unknown, we hypothesize that the magnitude of symptom severity evident in the luteal phase for all PMDD women, a defining feature of their disorder, may override the more subtle influence of abuse histories on symptom severity.

The persistent dysregulation in neuroendocrine and HR levels seen later in life in women with abuse histories is a remarkable feature of our findings. Although we did include women whose first abuse experience occurred as an adult (age range $=20-24$ years), $80 \%$ of our study sample consisted of women who had experienced childhood or adolescent abuse, with the majority experiencing abuse in childhood (60\%). Thus, many years, if not decades, had elapsed since some of the women in the present study had experienced abuse. This is consistent with the work of Wang and Mason (1999) showing persistent disturbance in HPA axis function in male combat veterans $40-50$ years following combat. This is also consistent with the observation of altered ACTH and cortisol responses to challenge in adult women with histories of childhood sexual abuse (Heim et al., 2001; Heim, Newport, et al., 2000). Thus, it is possible that dysregulation of neuroendocrine factors in women with abuse histories represents an adaptation gone awry if the stress axes continue to prepare the individual for a severe stressor that no longer exists but somehow remains encoded in the brain (Prange, 1999).

Finally, although we found that all women with abuse histories share a common dysregulation in NE and HR, and possibly in cortisol, we also obtained evidence, even after matching abused groups for depressive histories, that the biological correlates of abuse may differ for PMDD women. Specifically, consistent with results from our prior studies indicating that PMDD women may be more vulnerable to the influence of abuse histories on measures reflecting adrenergic physiology (Bunevicius et al., 2005; Girdler et al., 2003), only the PMDD women with abuse had greater VRI levels and greater BP levels at rest and during stress-effects not seen in the non-PMDD women. Because abused PMDD and abused non-PMDD women did not differ in HR or CI levels, the greater BP in abused PMDD women was likely mediated by their enhanced vascular tone. Studies using adrenergic receptor blockers in humans have shown that individual differences in total vascular resistance at rest and during mental stress are mediated, at least in part, by vascular $\alpha$-adrenergic receptors (Girdler, Hinderliter, \& Light, 1993). 
We have recently reported the results from a randomized, placebo-controlled, cross-over study that used a long-term clonidine challenge test (centrally acting, $\alpha 2$-receptor agonist) to investigate $\alpha 2$-adrenergic receptor mechanisms as a function of sexual abuse histories in 12 PMDD women (Bunevicius et al., 2005). We found that clonidine was associated with significantly greater reductions in resting and stress-induced BP and HR in the abused PMDD women compared with nonabused PMDD women, suggesting that abuse experiences may modify presynaptic $\alpha 2$-adrenoceptor function in PMDD. This interpretation is limited, however, by the relatively small sample size and by the lack of inclusion of non-PMDD controls. However, the potential patho-physiological role for $\alpha$-adrenoceptors in PMDD women with abuse histories comes from reports showing altered $\alpha$-adrenoceptor function in other psychiatric disorders, including mood disorders (Mokrani, Duval, Diep, Bailey, \& Macher, 2000; Siever et al., 1982), PTSD (Morris, Hopwood, Maguire, Norman, \& Schweitzer, 2004), and menstrual migraine (Facchinetti et al., 1989). More direct evidence comes from studies relating $\alpha 2$-adrenoceptor function directly to symptoms in PMDD women. For example, Gurguis et al. (1998) found positive correlations between luteal phase platelet $\alpha 2$ receptor density and premenstrual symptoms in PMDD women, and Halbreich, Piletz, Carson, Halaris, and Rojansky (1993) found increased $\alpha 2$-receptor binding in women with dysphoric PMS compared with symptom-free women and that binding was highly correlated with symptom severity (Halbreich et al., 1993). Although neither of these studies examined abuse histories, given the greater prevalence rates for abuse in PMDD (Girdler et al., 2003; Golding et al., 2000; Paddison et al., 1990), the possibility exists that their findings linking $\alpha 2$ adrenoceptor function to symptoms may reflect differential dys-regulation of $\alpha 2$-receptors in PMDD women with histories of abuse.

In conclusion, the results of our study indicate that histories of sexual and physical abuse are associated with persistent alterations in stress-responsive systems in women, even in the absence of current psychiatric illness or medication use. Our results also suggest, however, that PMDD women may be more vulnerable to the effects of abuse experiences on $\alpha$-adrenergic receptor function as only PMDD women with abuse exhibited greater vascular tone and blood pressure levels relative to nonabused PMDD women. As $\alpha$-adrenoceptor function has been linked to mood disorders (Mokrani et al., 2000; Siever et al., 1982), PTSD (Morris et al., 2004) and to premenstrual symptom severity in PMDD women (Gurguis et al., 1998; Halbreich et al., 1993), future studies examining $\alpha$-adrenoceptor function separately in PMDD and nonPMDD women as a function of abuse histories are clearly indicated and may have important treatment implications for PMDD—a heterogeneous disorder with respect to pathophysiological mechanisms (Halbreich, 1993), and one associated with a 50\% nonresponse rate to selective serotonin reuptake inhibitors (e.g., Pearlstein et al., 2000; Steiner et al., 1995).

\section{Acknowledgments}

This project was supported by National Institute of Mental Health Grants R01 MH51246 and GCRC RR00046. We are grateful to Dot Faulkner for manuscript preparation, to Heidi Lively and Katie Jorgensen for their roles as study coordinators, and to Unipath Diagnostics for their generous donation of Clearplan Easy® Ovulation prediction kits.

\section{References}

American Psychiatric Association. Diagnostic and statistical manual of mental disorders. Vol. 4th ed. Washington, DC: Author; 1994.

Badgley, R.; Allard, H.; McCormick, N.; Proudfoot, P.; Fortin, D.; Ogilvie, D., et al. Sexual offences against children. Vol. Vol. 1. Ottawa: Canadian Government Publishing Centre; 1984. Occurrence in the population; p. 175-193.

Bremner JD, Krystal JH, Southwick SM, Charney DS. Noradrenergic mechanisms in stress and anxiety: II. Clinical studies. SYNAPSE 1996;23:39-51. [PubMed: 8723134] 
Bremner JD, Vermetten E. Stress and development: Behavioral and biological consequences. Development and Psychopathology 2001;13:473-489. [PubMed: 11523844]

Bunevicius R, Hinderliter AL, Leserman J, Pedersen CA, Girdler SS. Histories of sexual abuse are associated with differential effects of clonidine on autonomic function in women with premenstrual dysphoric disorder. Biological Psychology 2005;69:281-296. [PubMed: 15925031]

Coplan JD, Andrews MW, Rosenblum LA, Owens MJ, Friedman S, Gorman JM, Nemeroff CG. Persistent elevations of cerebrospinal fluid concentrations of corticotrophin-releasing factor in adult nonhuman primates exposed to early-life stressors: Implications for the pathophysiology of mood and anxiety disorders. Proceedings of the National Academy of Sciences of the United States of America 1996;93:1619-1623. [PubMed: 8643680]

Facchinetti F, Martignoni E, Nappi G, Fioroni L, Sances G, Genazzani AR. Premenstrual failure of alphaadrenergic stimulation on hypothalamus-pituitary responses in menstrual migraine. Psychosomatic Medicine 1989;51:500-558.

Felitti VJ, Anda RF, Nordenberg D, Williamson DF, Spitz AM, Edwards V, et al. Relationship of childhood abuse and house-hold dysfunction to many of the leading causes of death in adults. American Journal of Preventive Medicine 1998;14:245-258. [PubMed: 9635069]

Finkelhor D, Hotaling G, Lewis IA, Smith C. Sexual abuse in a national survey of adult men and women: Prevalence, characteristics and risk factors. Child Abuse \& Neglect 1990;14:19-28. [PubMed: 2310970]

Girdler SS, Hinderliter AL, Light KC. Peripheral adrenergic receptor contributions to cardiovascular reactivity: Influence of race and gender. Journal of Psychosomatic Research 1993;37:177-193. [PubMed: 8385216]

Girdler SS, Sherwood A, Hinderliter AL, Leserman J, Costello NL, Straneva PA, et al. Biological correlates of abuse in women with premenstrual dysphoric disorder and health controls. Psychosomatic Medicine 2003;65:849-856. [PubMed: 14508031]

Golding JM, Taylor DL. Sexual assault history and premenstrual distress in two general population samples. Journal of Women's Health 1996;5:143-152.

Golding JM, Taylor DL, Menard L, King MJ. Prevalence of sexual abuse history in a sample of women seeking treatment for premenstrual syndrome. Journal of Psychosomatic Obstetrics \& Gynecology 2000;21:69-80. [PubMed: 10994179]

Gronwall DMA. Paced auditory serial-addition task: A measure of recovery from concussions. Perceptual and Motor Skills 1977;44:367-373. [PubMed: 866038]

Gurguis GNM, Yonkers KA, Phan SP, Blakeley JE, Williams A, Rush AJ. Adrenergic receptors in premenstrual dysphoric disorder: I. Platelet $\alpha_{2}$ receptors: $G_{i}$ protein coupling, phase of menstrual cycle, and prediction of luteal phase symptom severity. Biological Psychiatry 1998;44:600-609. [PubMed: 9787884]

Halbreich U, Piletz JE, Carson S, Halaris A, Rojansky N. Increased imidazoline and alpha 2 adrenergic binding in platelets of women with dysphoric premenstrual syndromes. Biological Psychiatry 1993;34:676-686. [PubMed: 7904832]

Heim C, Ehlert U, Hellhammer DH. The potential role of hypocortisolism in the pathophysiology of stress-related bodily disorders. Psychoneuroendocrinology 2000a;25:1-35. [PubMed: 10633533]

Heim C, Newport DJ, Bonsall R, Miller AH, Nemeroff CB. Altered pituitary-adrenal axis responses to provocative challenge tests in adult survivors of childhood abuse. American Journal of Psychiatry 2001;158:575-581. [PubMed: 11282691]

Heim C, Newport DJ, Heit S, Graham YP, Wilcox M, Bonsall R, et al. Pituitary-adrenal and autonomic responses to stress in women after sexual and physical abuse in childhood. Journal of the American Medical Association 2000b;284:592-597. [PubMed: 10918705]

Kaufman J, Birmaher B, Perel J, Dahl RE, Moreci P, Nelson B, et al. The corticotrophin-releasing hormone challenge in depressed abused, depressed nonabused, and normal control children. Biological Psychiatry 1997;42:669-679. [PubMed: 9325560]

Kendler KS, Builk CM, Silberg J, Hettema JM, Myers J, Prescott CA. Childhood sexual abuse and adult psychiatric and substance use disorders in women. Archives of General Psychiatry 2000;57:953959. [PubMed: 11015813] 
Kirschbaum C, Klauer T, Filip SH, Hellhammer DS. Sex-specific effects of social support on cortisol and subjective responses to acute psychological stress. Psychosomatic Medicine 1995;57:23-31. [PubMed: 7732155]

Kirschbaum C, Pirke K-M, Hellhammer DH. The "Trier Social Stress Test"-A tool for investigating psychobiological stress responses in a laboratory setting. Neuropsychobiology 1993;28:76-81. [PubMed: 8255414]

Kirschbaum C, Prussner JC, Stone AA, Federenko I, Gaab J, Lintz D, et al. Persistent high cortisol responses to repeated psychological stress in a subpopulation of healthy men. Psychosomatic Medicine 1995;57:468-474. [PubMed: 8552738]

Klatzkin RR, Morrow AL, Light KC, Pedersen CA, Girdler SS. Histories of depression, allopregnanolone responses to stress, and premenstrual symptoms in women. Biological Psychology 2005;71:2-11. [PubMed: 15951099]

Kubicek WG, Krnegis JN, Patterson RP, Witsoe DA, Mattson RH. Development and evaluation of an impedance cardiac output system. Aerospace Medicine 1966;37:1208-1212. [PubMed: 5339656]

Kudielka BM, Kirschbaum C. Sex differences in HPA axis responses to stress: A review. Biological Psychology 2005;69:113-132. [PubMed: 15740829]

Ladd CO, Owens MJ, Nemeroff CB. Persistent changes in corticotrophin-releasing factor neuronal systems induced by maternal deprivation. Endocrinology 1996;137:1212-1218. [PubMed: 8625891]

Lemieux AM, Coe CL. Abuse-related posttraumatic stress disorder: Evidence for chronic neuroendocrine activation in women. Psychosomatic Medicine 1995;57:105-115. [PubMed: 7792368]

Leonard BE. The role of noradrenaline in depression: A review. Journal of Psychopharmacology 1997;11:S39-S47. [PubMed: 9438232]

Leserman J, Drossman DA, Li Z. The reliability and validity of a sexual and physical abuse history questionnaire in female patients with gastrointestinal disorders. Behavioral Medicine 1995;21:141150. [PubMed: 8789650]

Leserman J, Drossman DA, Li Z, Toomey TC, Nachman G, Glogau L. Sexual and physical abuse history in gastroenterology practice: How types of abuse impact health status. Psychosomatic Medicine 1996;58:4-15. [PubMed: 8677288]

Leserman J, Li Z, Drossman DA, Hu YJB. Selected symptoms associated with sexual and physical abuse history among female patients with gastrointestinal disorders: The impact on subsequent health care visits. Psychological Medicine 1998;28:417-425. [PubMed: 9572098]

MacMillan HL, Fleming JE, Trocme N, Boyle MH, Wong M, Racine YA, et al. Prevalence of child physical and sexual abuse in the community: Results from the Ontario Health Supplement. JAMA 1997;278:131-135. [PubMed: 9214528]

McCauley J, Kern DE, Kolodner K, Dill L, Schroeder AF, DeChant HK, et al. Clinical characteristics of women with a history of childhood abuse: Unhealed wounds. JAMA 1997;277:1362-1368. [PubMed: 9134941]

Metzger LJ, Orr SP, Ahern CE, Berry NJ, Lasko NB, Pitman RK. Physiologic reactivity to startling tones in women with posttraumatic stress disorder. Journal of Abnormal Psychology 1999;108:347-352. [PubMed: 10369045]

Mokrani M, Duval F, Diep TS, Bailey PE, Macher JP. Multihormonal responses to clonidine in patients with affective and psychotic symptoms. Psychoneuroendocrinology 2000;25:741-752. [PubMed: 10938452]

Morris P, Hopwood M, Maguire K, Norman T, Schweitzer I. Blunted growth hormone response to clonidine in post-traumatic stress disorder. Psychoneuroendocrinology 2004;29:269-278. [PubMed: 14604605]

Newport DJ, Heim C, Bonsall R, Miller AH, Nemeroff CB. Pituitary-adrenal responses to standard and low-dose dexamethasone suppression tests in adult survivors of child abuse. Biological Psychiatry 2004;55:10-20. [PubMed: 14706420]

Orr SP, Lasko NB, Metzger LJ, Ahern CE, Berry NJ, Pitman RK. Psychophysiologic assessment of women with posttraumatic stress disorder resulting from childhood sexual abuse. Journal of Consulting and Clinical Psychology 1998;66:906-912. [PubMed: 9874903] 
Paddison PL, Gise LH, Lebovits A, Strain JJ, Cirasole DM, Levine JP. Sexual abuse and premenstrual syndrome: Comparison between a lower and higher socioeconomic group. Psychosomatics 1990;31:265-272. [PubMed: 2388980]

Pearlstein TB, Frank E, Rivera-Tova A, Thoft JS, Jacobs E, Mieczkowski TA. Prevalence of Axis I and Axis II disorders in women with late luteal phase dysphoric disorder. Journal of Affective Disorders 1990;20:129-134. [PubMed: 2148327]

Pearlstein TB, Halbreich U, Batzar ED, Brown CS, Endicott J, Frank E, et al. Psychosocial functioning in women with premenstrual dysphoric disorder before and after treatment with sertraline or placebo. Journal of Clinical Psychiatry 2000;61:101-109. [PubMed: 10732657]

Pedersen CA, Stern RA, Pate J, Senger MA, Bowes WA, Mason GA. Thyroid and adrenal measures during late pregnancy and the puerperium in women who had been major depressed or who become dysphoric postpartum. Journal of Affective Disorders 1993;29:201-211. [PubMed: 8300979]

Prange AJ Jr. Thyroid axis sustaining hypothesis of posttraumatic stress disorder. Psychosomatic Medicine 1999;61:139-140. [PubMed: 10204963]

Reid, RL. Premenstrual syndrome. In: Leventha, JM.; Hoffman, JJ.; Keith, LG.; Taylor, PJ., editors. Obstetrics, gynecology and fertility. Chicago: Year Book Medical; 1985. p. 4-57.

Resnick HS, Kilpatric DG, Dansky BS, Saunders BE, Best CL. Prevalence of civilian trauma and posttraumatic stress disorder in a representative national sample of women. Journal of Consulting and Clinical Psychology 1993;61:984-991. [PubMed: 8113499]

Resnick HS, Yehuda R, Pitman RK, Foy DW. Effect of previous trauma on acute plasma cortisol level following rape. American Journal of Psychiatry 1995;152:1675-1677. [PubMed: 7485635]

Sherwood A, Allen MT, Fahrenbert J, Kelsey RM, Lovallo WR, van Doormen LJP. Methodological guidelines for impedance cardiography. Psychophysiology 1990;27:1-23. [PubMed: 2187214]

Siever LJ, Uhde TW, Silberman EK, Lake CR, Jimerson DC, Risch SC, Kalin NH, Murphy DL. Evaluation of alpha-adrenergic responsiveness to clonidine challenge and noradrenergic metabolism in the affective disorders and their treatment. Psychopharmacology Bulletin 1982;18:118-119. [PubMed: 6296907]

Spitzer RL, Williams JB, Gibbon M, First MB. The Structured Clinical Interview for $D S M-I I I-R$ (SCID): I. History, rationale, and description. Archives of General Psychiatry 1992;49:624-629. [PubMed: 1637252]

Stein MB, Yehuda R, Koverola C, Hanna C. Enhanced dexamethasone suppression of plasma cortisol in adult women traumatized by childhood sexual abuse. Biological Psychiatry 1997;42:680-686. [PubMed: 9325561]

Steiner M, Steinberg S, Stewart D, Carter D, Berger C, Reid R, Grover D, Streiner D. Fluoxetine in the treatment of premenstrual dysphoria. New England Journal of Medicine 1995;332:1529-1534. [PubMed: 7739706]

Wang S, Mason J. Elevations of serum $\mathrm{T}_{3}$ levels and their association with symptoms in World War II veterans with combatrelated posttraumatic stress disorder: Replication of findings in Vietnam combat veterans. Psychosomatic Medicine 1999;61:131-138. [PubMed: 10204962]

Weissman MM, Olfson M. Depression in women: Implications for health care research. Science 1995 August 11;269:799-801. [PubMed: 7638596]

Yehuda, R.; Giller, EL.; Levengood, RA.; Southwick, SM.; Siever, LJ. Hypothalamic-pituitary-adrenal (HPA) functioning in post-traumatic stress disorder: The concept of the stress response spectrum. In: Friedman, MJ.; Channey, DS.; Deutch, AY., editors. Neurobiological and clinical consequences of stress: From normal adaptation to PTSD. New York: Raven Press; 1995. p. 367-380.

Young EA, Aggen SH, Prescott CA, Kendler KS. Similarity in saliva cortisol measures in monozygotic twins and the influence of past major depression. Biological Psychiatry 2000;48:70-74. [PubMed: 10913510]

Young EA, Breslau N. Cortisol and catecholamines in posttraumatic stress disorder. Archives of General Psychiatry 2004;61:394-401. [PubMed: 15066898]

Young EA, Tolman R, Witkowski K, Kaplan G. Salivary cortisol and posttraumatic stress disorder in a low-income community sample of women. Biological Psychiatry 2004;55:621-626. [PubMed: 15013831] 

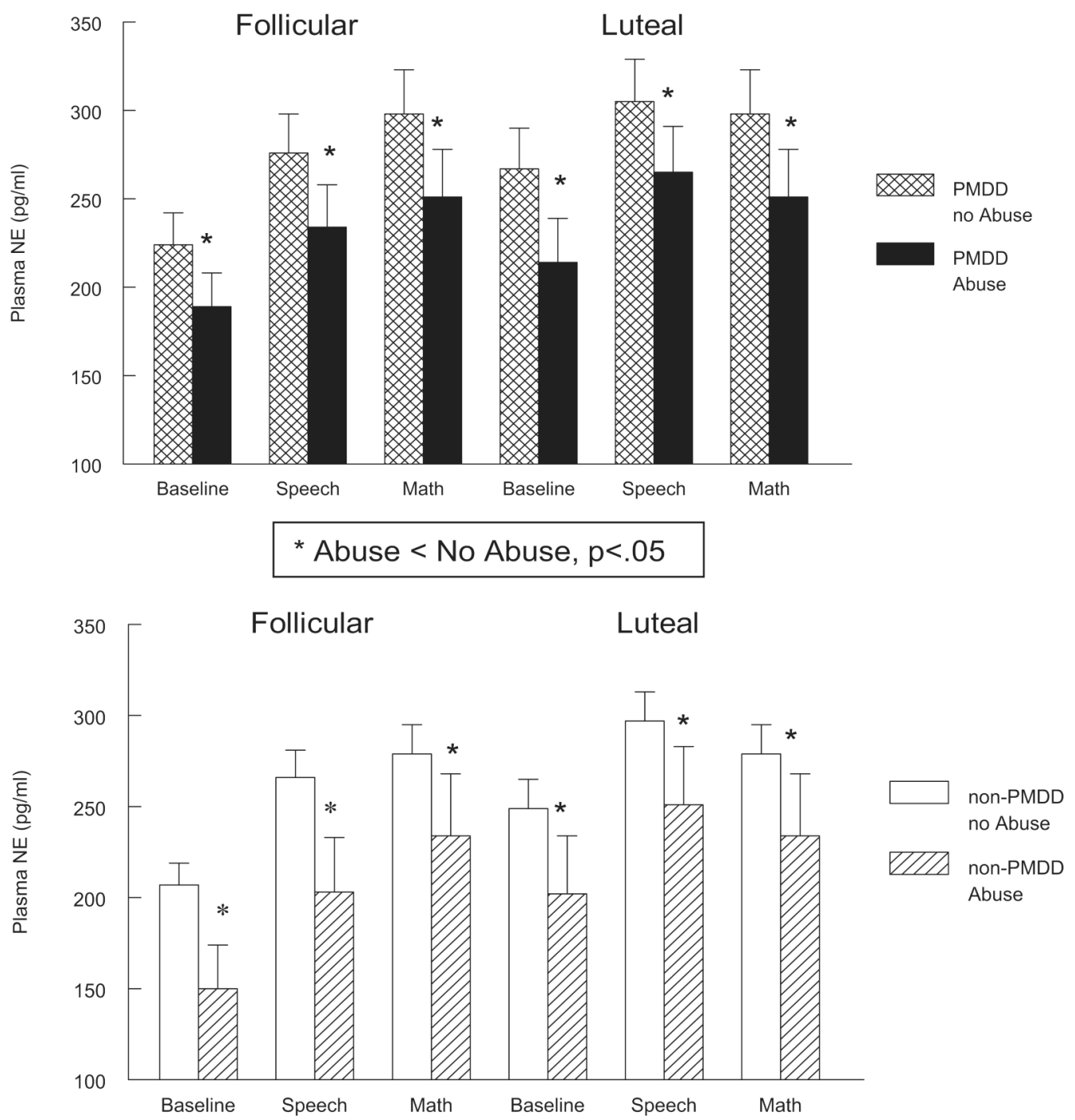

Figure 1.

Plasma norepinephrine (NE; pg/ml) at baseline rest and during stressors in PMDD (top panel) and non-PMDD women (bottom panel) as a function of abuse histories and menstrual cycle phase. PMDD = premenstrual dysphoric disorder. Error bars represent the standard error of the mean. 

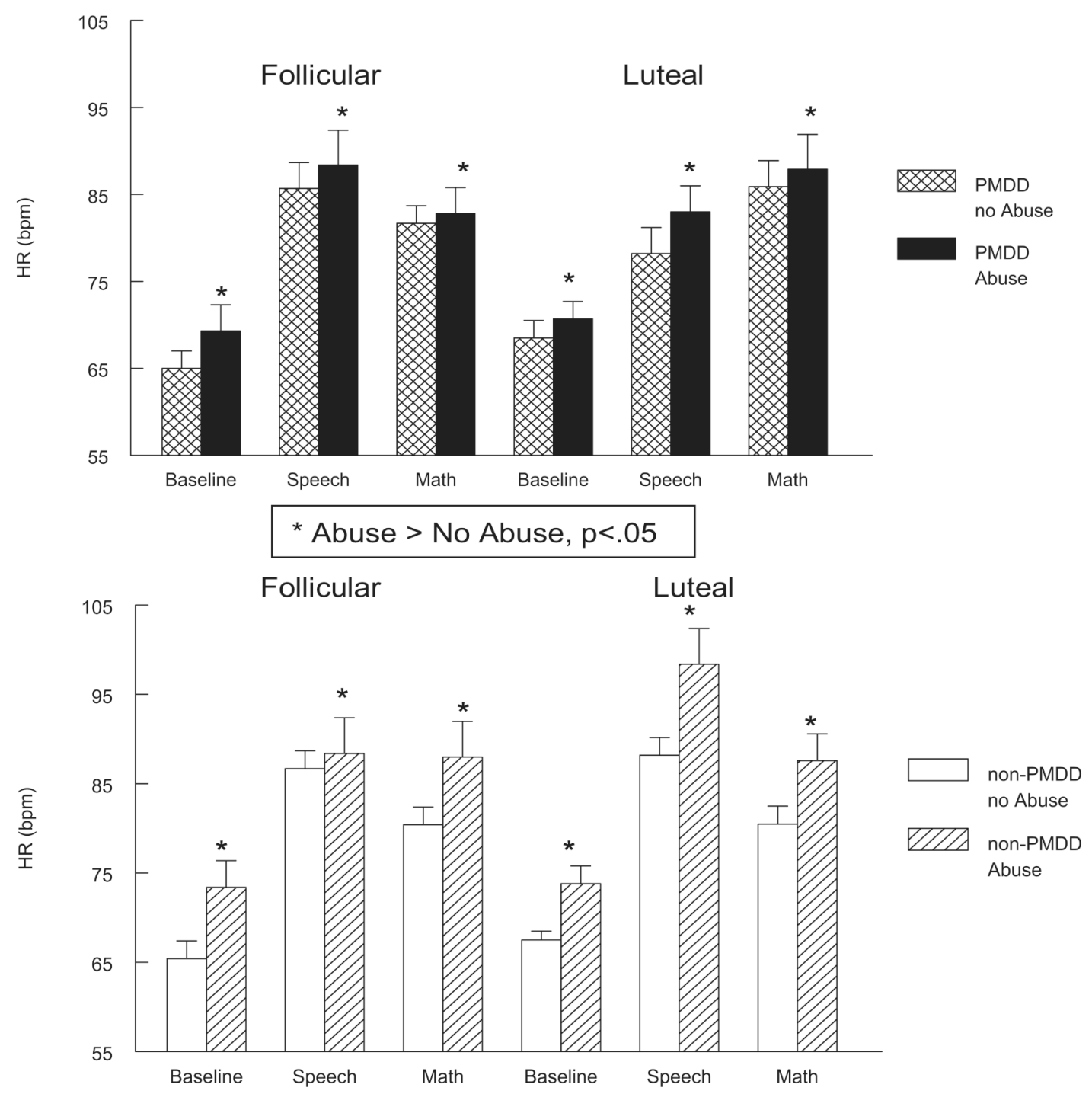

Figure 2.

Heart rate (HR, in beats per minute [bpm]) at baseline rest and during stressors in PMDD women (top panel) and non-PMDD women (bottom panel) as a function of abuse history and menstrual cycle phase. PMDD = premenstrual dysphoric disorder. Error bars represent the standard error of the mean. 

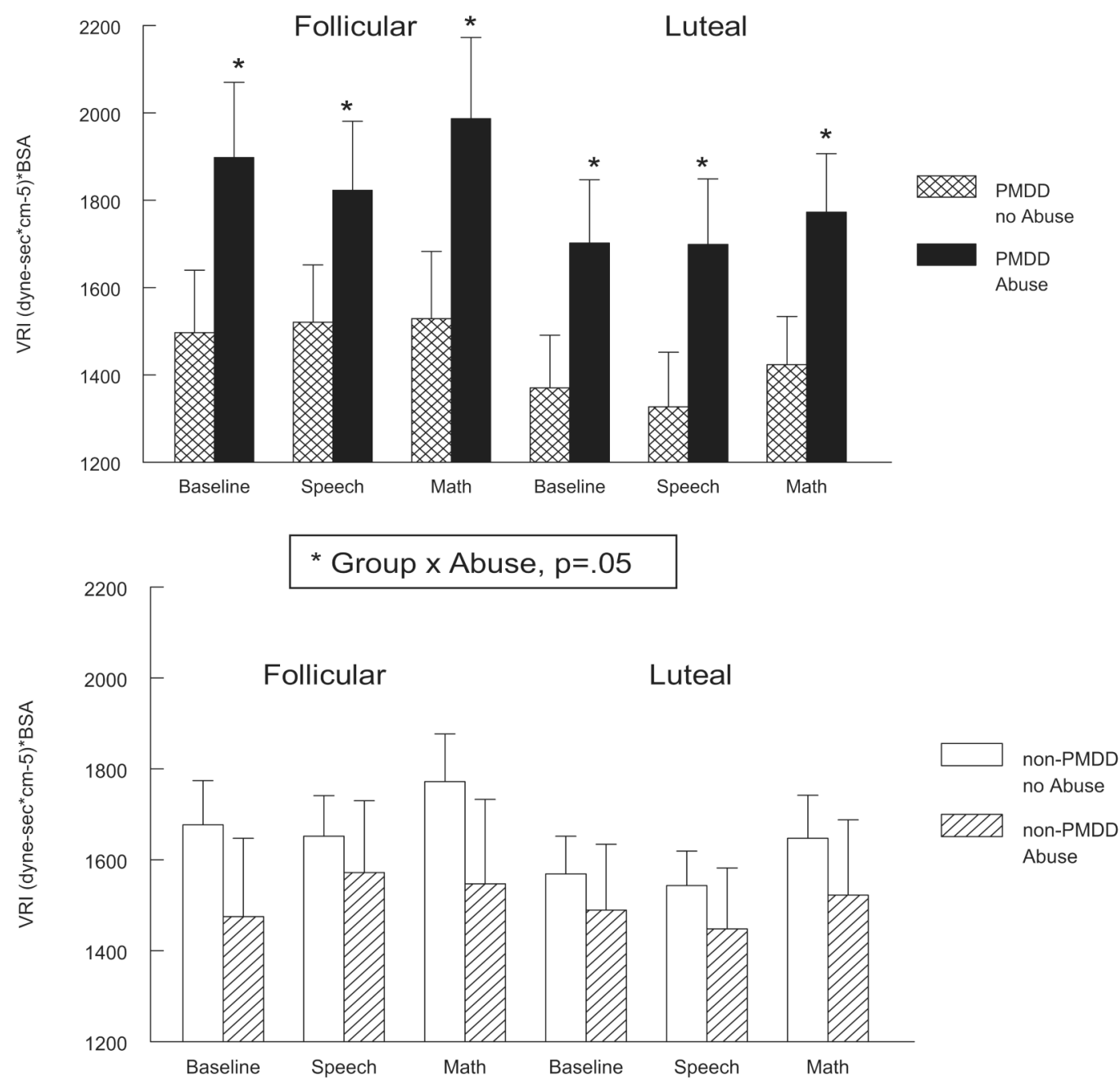

Figure 3.

Vascular resistance index (VRI; [dyne $-\sec \times \mathrm{cm}^{-5}$ ] $\times$ BSA) at baseline rest and during stressors in PMDD women (top panel) and non-PMDD women (bottom panel) as a function of abuse history and menstrual cycle phase. $\mathrm{BSA}=$ body surface area; $\mathrm{PMDD}=$ premenstrual dysphoric disorder. Error bars represent the standard error of the mean. 

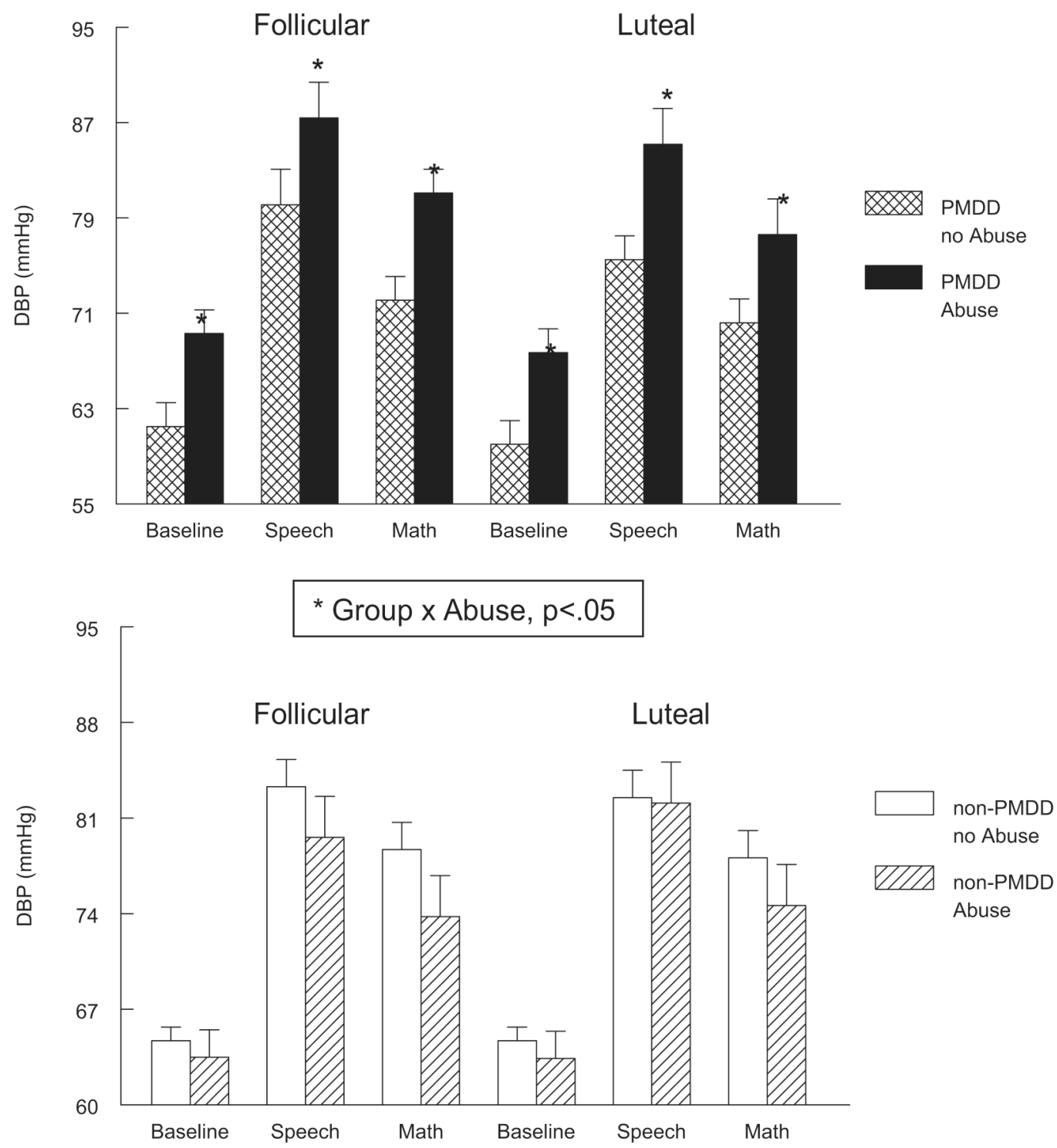

Figure 4.

Diastolic blood pressure (DBP; $\mathrm{mmHg}$ ) at baseline rest and during stressors in PMDD women (top panel) and non-PMDD women (bottom panel) as a function of abuse history and menstrual cycle phase. Error bars represent the standard error of the mean. 
Table 1

Demographics and Psychiatric History Variables in PMDD and Non-PMDD Women as a Function of Abuse Histories

\begin{tabular}{|c|c|c|c|c|}
\hline \multirow[b]{2}{*}{ Variable } & \multicolumn{2}{|c|}{ PMDD } & \multicolumn{2}{|c|}{ Non-PMDD } \\
\hline & $\begin{array}{r}\text { Abuse } \\
(n=12)\end{array}$ & $\begin{array}{r}\text { No abuse } \\
(n=13)\end{array}$ & $\begin{array}{r}\text { Abuse } \\
(n=12)\end{array}$ & $\begin{array}{r}\text { No abuse } \\
(n=\mathbf{3 0})\end{array}$ \\
\hline \multicolumn{5}{|c|}{ Age (years) } \\
\hline$M$ & 35 & 31 & 34 & 35 \\
\hline$S D$ & 1.9 & 1.8 & 1.9 & 1.2 \\
\hline \multicolumn{5}{|l|}{$\mathrm{BMI}^{a}$} \\
\hline$M$ & 27.3 & 21.9 & 25.0 & 24.7 \\
\hline$S D$ & 1.3 & 1.2 & 1.3 & 0.8 \\
\hline \multicolumn{5}{|c|}{$\begin{array}{l}\text { Psychiatric history } \\
\text { Depression }^{b}\end{array}$} \\
\hline$n$ & 8 & 6 & 9 & 10 \\
\hline$\%$ & 67 & 46 & 75 & 33 \\
\hline \multicolumn{5}{|l|}{$\mathrm{PTSD}^{a}$} \\
\hline$n$ & 4 & 0 & 1 & 0 \\
\hline$\%$ & 33 & & 8 & \\
\hline \multicolumn{5}{|l|}{ Anxiety } \\
\hline$n$ & 2 & 3 & 3 & 2 \\
\hline$\%$ & 17 & 23 & 25 & 7 \\
\hline \multicolumn{5}{|c|}{ Substance } \\
\hline$n$ & 2 & 0 & 3 & 3 \\
\hline$\%$ & 17 & & 25 & 10 \\
\hline \multicolumn{5}{|c|}{ Eating disorders } \\
\hline$n$ & 2 & 2 & 1 & 1 \\
\hline$\%$ & 17 & 15 & 8 & 3 \\
\hline
\end{tabular}

Note. $\mathrm{PMDD}=$ premenstrual dysphoric disorder; $\mathrm{BMI}=$ body mass index PTSD = posttraumatic stress disorder.

${ }^{a}$ PMDD with abuse $>$ PMDD no abuse, $p<.05$.

${ }^{b}$ Abuse $>$ no abuse, $p<.01$. 
Girdler et al.

Page 20

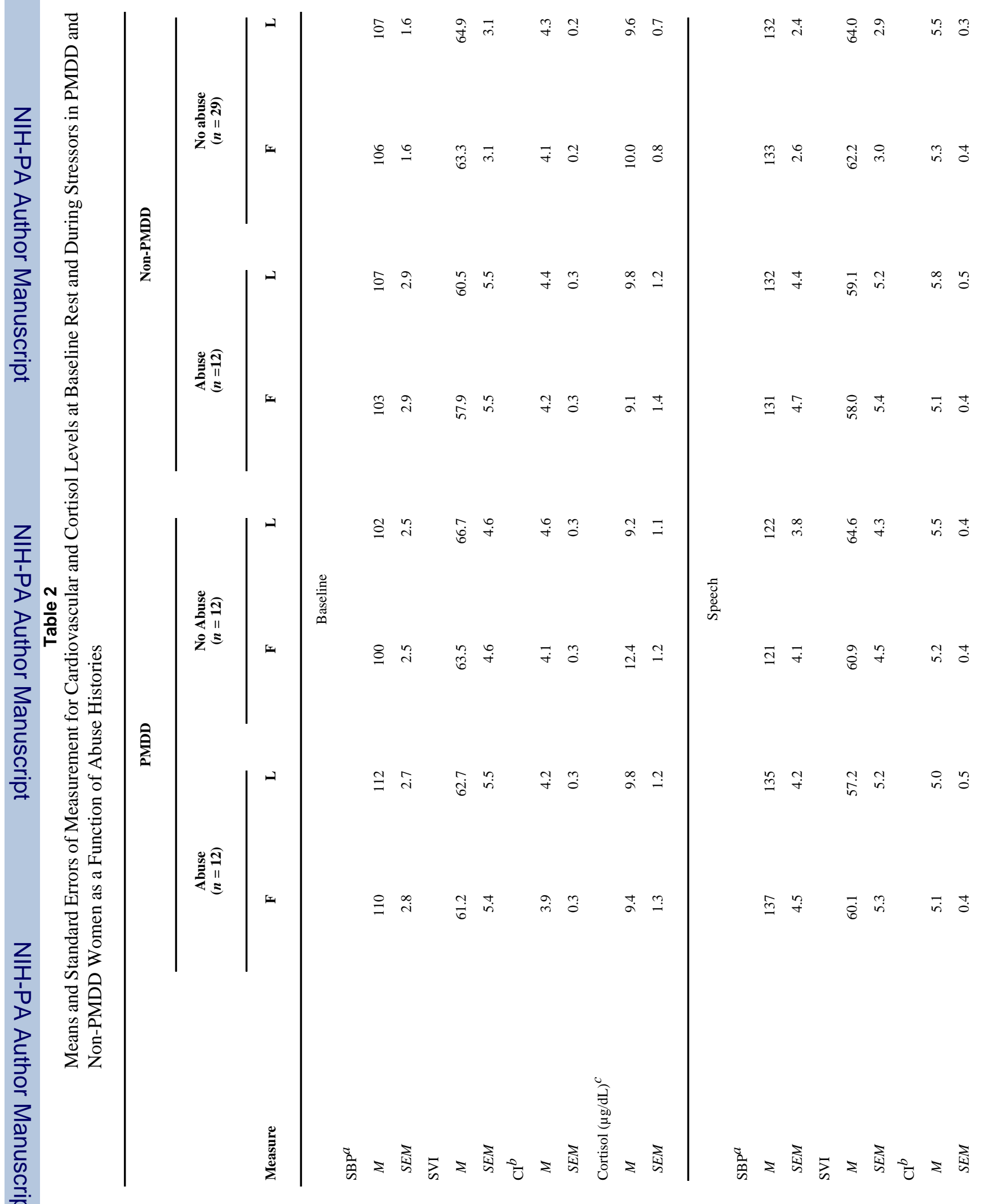

Health Psychol. Author manuscript; available in PMC 2009 September 24. 
Girdler et al.

Page 21

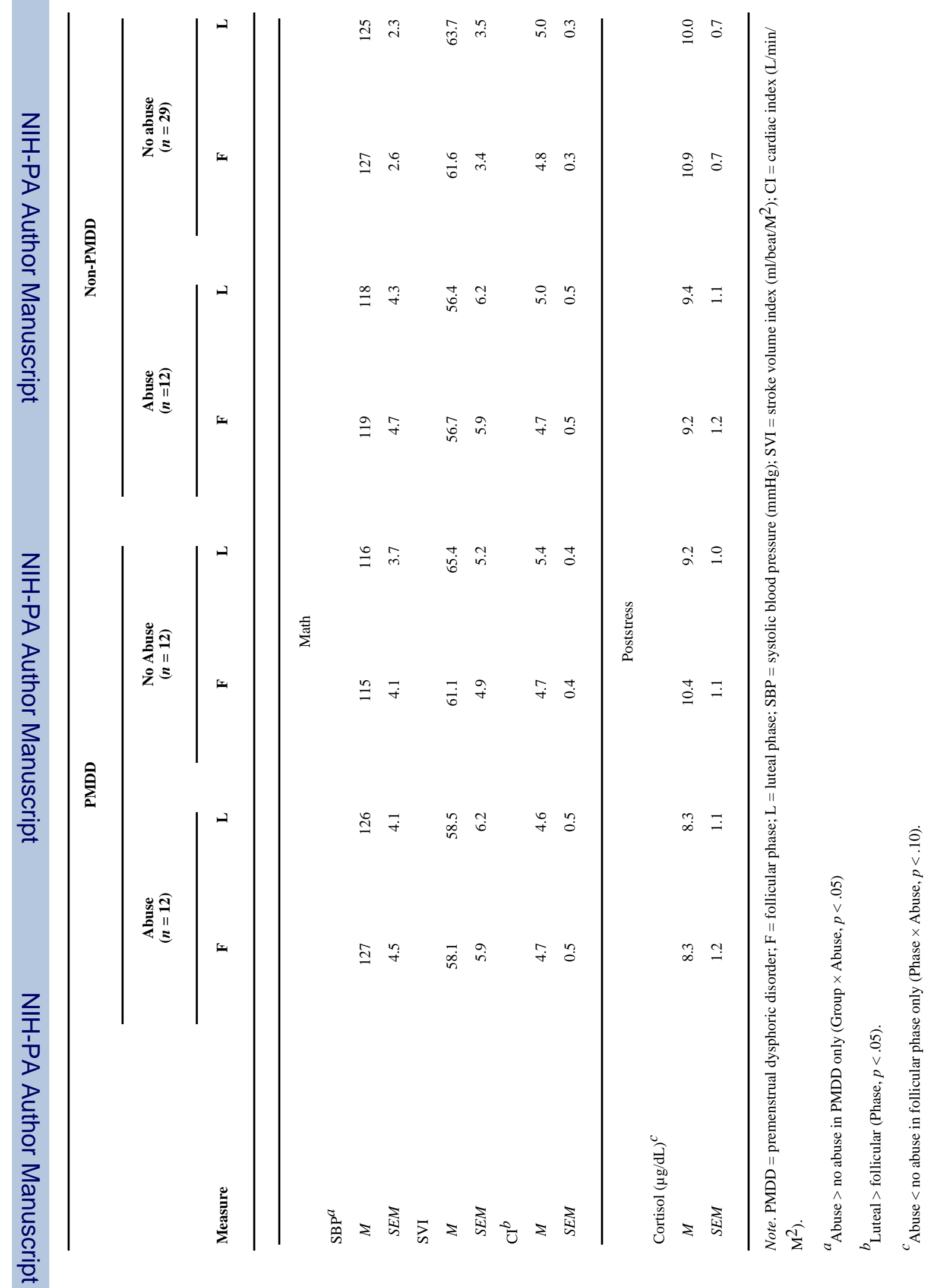

Health Psychol. Author manuscript; available in PMC 2009 September 24. 


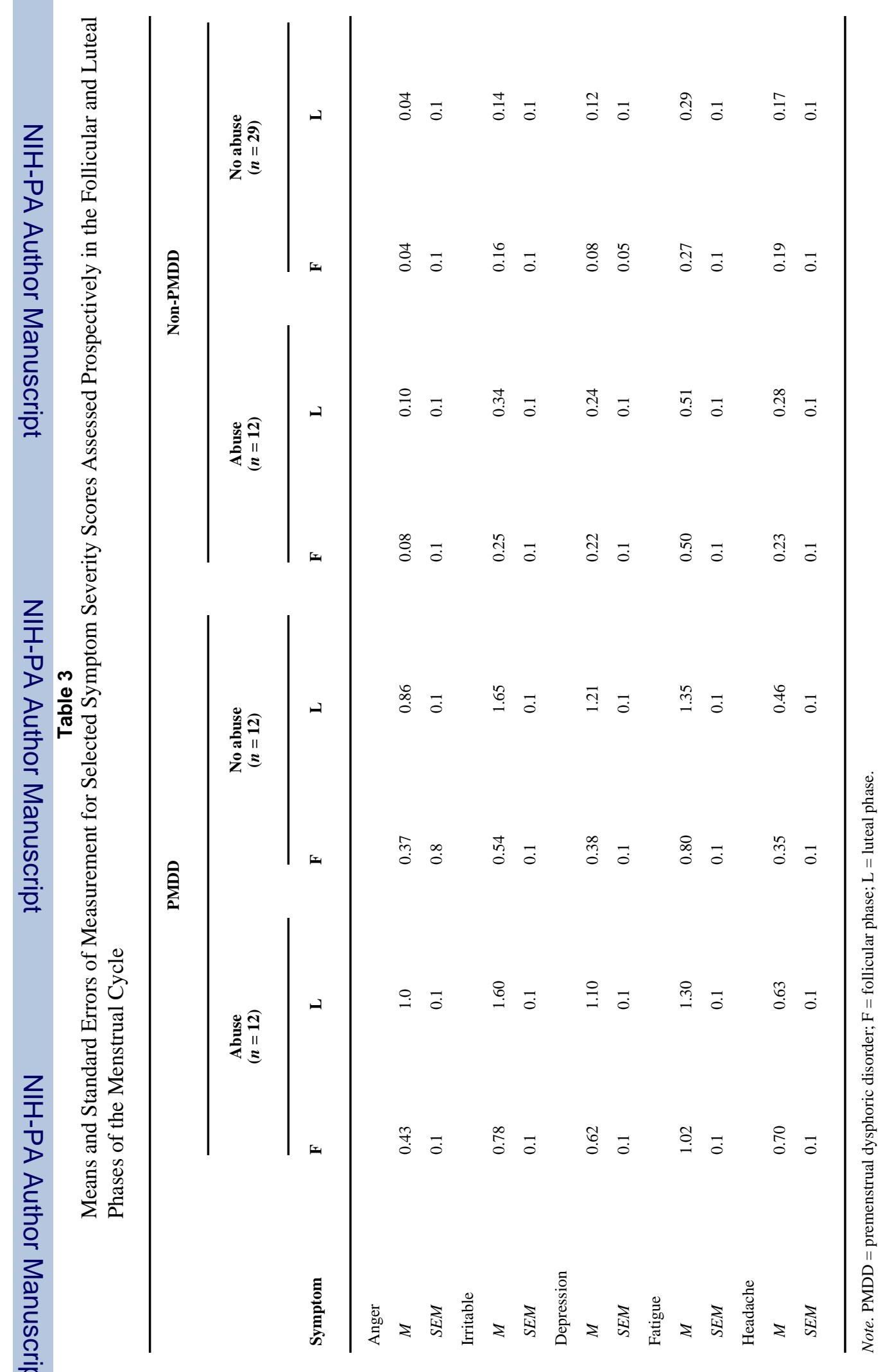

